\title{
Preparation of Micro-Iron Ore Tailings by Wet-Grinding and Its Application in Sulphoaluminate Cement
}

\author{
Yingchun Yang ${ }^{1, *}$ Liqing Chen ${ }^{1}$, Xingdong Sun ${ }^{1}$ and Yuguang $\mathrm{Mao}^{2}$ \\ ${ }^{1}$ College of Engineering, Anhui Agricultural University, Hefei, 230036, China \\ ${ }^{2}$ College of Civil Engineering, Hunan University, Changsha, 410082, China \\ ${ }^{\star}$ Corresponding Author: Yingchun Yang. Email: yangyingchun1983@163.com \\ Received: 06 May 2021 Accepted: 21 June 2021
}

\begin{abstract}
Herein, micro iron ore tailings (micro-IOTs) were prepared by wet-grinding and applied to improve sulphoaluminate cement (SAC) performance. The physicochemical properties of micro-IOTs were investigated by particle size analysis, XRD, and XPS. The hydrates trait and the hydration mechanism of micro-IOTs-SAC composite were studied by XRD, TGA, MIP, and SEM. The results demonstrated that micro-IOTs with an average grain diameter of $517 \mathrm{~nm}$ could be obtained by wet-grinding. The setting time of SAC gradually decreased with increasing micro-IOTs content. By adding $2 \%$ micro-IOTs, the compressive strengths of SAC pastes were enhanced about $22 \%$ and $10 \%$ at $4 \mathrm{~h}$ and $28 \mathrm{~d}$, respectively. Moreover, the addition of micro-IOTs accelerated ettringite precipitation and changed its morphology, resulting in early strength improvement of the binary system. And increased later strength by micro-IOTs was closely related to the high content of $\mathrm{AH}_{3}$, fine pore structure, and high hydration degree of SAC. The findings suggested one new approach to utilize iron ore tailings in cementbased materials.
\end{abstract}

\section{KEYWORDS}

Micro iron ore tailings; sulphoaluminate cement; ettringite; compressive strength; hydration process

\section{Introduction}

Iron ore tailings (IOTs) are inevitable by-products generated from iron ore sorting operations $[1,2]$. As the iron and steel industry develops, discharged IOTs increase annually [3]. According to estimates, the current accumulated amount of IOTs has surpassed five billion tons, reaching over $80 \%$ of the national industrial solid waste in China [4]. Without proper waste management, most IOTs are directly disposed of in tailing dams or rivers, occupying a great lot of land, and leading to severe environmental pollution and unsafe risks [5,6]. To face the considerable harm of tailings, using IOTs safely and efficiently has been a hot topic of social concern $[7,8]$. Over the years, considerable research on recycling iron tailings has been carried out in various fields $[9,10]$. Considering that the major chemical components of IOTs are $\mathrm{SiO}_{2}$, $\mathrm{Al}_{2} \mathrm{O}_{3}, \mathrm{Fe}_{2} \mathrm{O}_{3}$, and $\mathrm{CaO}$, using IOTs to prepare construction and building materials has attracted much attention [11]. It is worth mentioning that the application mode of IOTs in building materials depends on their particle size. The IOTs with particle diameters between 0.16 and $4.75 \mathrm{~mm}$ are usually used to replace natural sand to prepare concrete [12-14]. Many studies are also underway to apply these IOTs in 
preparing building ceramics [15-17], autoclaved aerated concrete [18,19], and wall materials [20-22]. In recent years, some IOTs have been ground into fine powders (particle size $<0.16 \mathrm{~mm}$ ) to improve ore dressing efficiency. Since these IOTs powders have no physical or chemical activity, they are challenging to use and transform. Several studies are currently underway to stimulate their activity by mechanical grinding and use IOTs as supplementary cementitious materials in cement-based materials [23-25]. It was demonstrated in these studies that utilizing IOTs powders as cement replacement had significant economic and environmental benefits. However, much work so far has focused on utilizing IOTs in Portland cement (PC). There is a lack of research on the feasibility of applying IOTs powder to sulphoaluminate cement (SAC) systems.

In fact, SAC has been accepted as an eco-friendly cementitious material due to lower energy consumption and less $\mathrm{CO}_{2}$ emission than PC [26-29]. However, SAC's cost is higher than PC due to costly raw material, and SAC's late strength usually develops slowly or even decreases slightly because the hydrated product ettringite is easy to decompose or transform, limiting its wide application in engineering [30]. According to previous reports, SAC performance could be improved by adding appropriate amount of nanometer material due to the excellent filling and nucleation effect [31-34]. However, nanometer material price is usually relatively high, which will inevitably further increase SAC's cost. Finding suitable mineral admixtures may be a better choice to expand SAC's application fields. However, traditional active admixtures, such as fly ash and slag, are complicated to significantly improve the performance of SAC due to the low alkalinity of SAC. Thus, this study aims to prepare micron-sized IOTs powders as an admixture to improve SAC's performance.

However, it was complicated to obtain micron-sized IOTs powders by traditional mechanical grinding due to high energy consumption and inevitable particle agglomeration. It is critical to developing more effective methods to refine these IOT powders. Wet grinding refers to a technology to refine solid powder under water-based conditions, achieving the dual effects of mechanical and chemical activation [35,36]. For water-containing inert materials, wet grinding also can save cost and reduce energy consumption without pre-drying [37]. Zhang et al. [38] found that the activity of ground granulated blast furnace slag and gypsum dissolution could be promoted using wet grinding technology. Yang et al. confirmed that wet milling was an ecologically friendly technology. And the pozzolanic activity of fly ash was significantly improved by wet grinding [39]. It was also reported that micron-size lithium slag could be obtained by wet milling, and the microparticles could be used as an accelerator to promote PC's early strength [36]. Our previous research demonstrated that IOTs with D50 $=6.203 \mu \mathrm{m}$ were very difficult to obtain through dry grinding, but could be easily obtained using wet grinding technology [40]. These guided micro-IOTs slurry preparation by wet grinding, suggesting a new approach toward high-value utilization of IOTs powder in SAC system.

To this end, the micro-IOTs slurry was prepared by wet grinding to be utilized in SAC to improve SAC performance. The physical and chemical changes of IOTs were investigated, and the effect of micro-IOTs on performance of SAC pastes was evaluated by setting time and compressive strength. Furthermore, thermogravimetric analysis (TGA), X-ray diffraction (XRD), mercury intrusion porosimetry (MIP), and scanning electron microscopy (SEM) were utilized to illustrate the mechanism behind the promoted strength. Finally, a new approach to recycle IOTs in cement and concrete fields was expected to emerge.

\section{Materials and Methods}

\subsection{Materials}

Commercial fast hardening SAC following GB 20472-2006 [41], was used in this study. The raw iron ore tailings (RIOTs) were obtained from a mining enterprise in Huoqiu County of Anhui Province of China, and a small amount of larger particles was removed using a $0.18 \mathrm{~mm}$ sieve before the experiment. The chemical compositions of SAC and RIOTs were tested by XRF (see Table 1). According to the chemical 
composition of RIOTs, the basicity $\mathrm{R}=\mathrm{CaO} / \mathrm{SiO}_{2}$ was only 0.08 , indicating that RIOTs used here was with a very low pozzolanic reactivity [42], and thus it posed a tremendous technical challenge to apply it to cementbased materials.

Table 1: Chemical compositions (by mass) of SAC and RIOTs (\%)

\begin{tabular}{lllllllll}
\hline Raw material & $\mathrm{SiO}_{2}$ & $\mathrm{Al}_{2} \mathrm{O}_{3}$ & $\mathrm{CaO}$ & $\mathrm{Fe}_{2} \mathrm{O}_{3}$ & $\mathrm{MgO}$ & $\mathrm{SO}_{3}$ & $\mathrm{~K}_{2} \mathrm{O}$ & $\mathrm{Na}_{2} \mathrm{O}$ \\
\hline SAC & 9.73 & 27.24 & 44.30 & 1.89 & 1.05 & 13.06 & 1.05 & 0.283 \\
RIOTs & 50.26 & 4.22 & 4.19 & 24.36 & 14.44 & 0.34 & 0.73 & 0.55 \\
\hline
\end{tabular}

\subsection{Preparation of Micro-IOTs}

The micro-IOTs slurry was prepared in a planetary ball mill with four grinding pots. Each grinding pot included five specification agate balls, with a mass ratio of $10 \mathrm{~mm}: 8 \mathrm{~mm}: 5 \mathrm{~mm}: 3 \mathrm{~mm}: 1 \mathrm{~mm}=1: 3: 6: 2: 2$. The total mass of the agate balls was about $60 \mathrm{~g}$ in each grinding pot. A commercially available polycarboxylate superplasticizer (PCE) was used as the dispersant to improve the grinding efficiency [39]. RIOTs (20 g), PCE $(0.2 \mathrm{~g})$, and water $(20 \mathrm{~g})$ were separately weighed and put into the grinding pot, and the mixture was ground for $2 \mathrm{~h}$ with a motor speed of $600 \mathrm{r} / \mathrm{m}$. And then the agate balls were separated, and the micro-IOTs slurry was obtained. Considering that many larger IOTs particles were attached to the bottom of the grinding pot and the surface of the grinding ball in the separation process, the solid-liquid ratio of the micro-IOTs slurry was recalibrated by experiments. $10 \mathrm{~g}$ of the slurry was dried, and the weight of solid was $4 \mathrm{~g}$, which meant that the weight ratio of (micro-IOTs + PCE) and water was constant at 4:6 in the slurry.

\subsection{Methods}

\subsubsection{Determination of Characteristics of Micro-IOTs}

The particle size distributions of RIOTs and SAC were measured by Malvern 2000, and the particle size distribution of micro-IOTs was measured by Malvern ZS90. It should be noted that the micro-IOTs slurry was dispersed by ultrasonic for $40 \mathrm{~s}$ before testing. Moreover, the micro-IOTs were dried in an oven at $60^{\circ} \mathrm{C}$ for $24 \mathrm{~h}$, and the phase and chemical structure of RIOTs and micro-IOTs were assessed by XRD and X-ray photoelectron spectroscopy (XPS), respectively.

\subsubsection{Setting Time}

The paste formulation was shown in Table 2. The binary binders were prepared with a water/binder weight ratio of 0.4 , and the SAC was replaced by micro-IOTs with different ratios $(0 \%, 2 \%, 4 \%$, and $8 \%$ ). It is noted that micro-IOTs were directly added in a slurry state, and differences in dosages of PCE and water brought by micro-IOTs slurry were also considered. To achieve a homogeneous dispersion in SAC paste, the micro-IOTs were premixed with water and PCE for three minutes using a magnetic stirrer, then SAC and liquid (PCE/water or micro-IOTs/PCE/water suspension) were placed in a steel bowl and stirred in a manual mixer at $2000 \mathrm{rpm}$ for one minute. After that, the setting time of binary binder was conducted with Vicat apparatus according to requirements of GB/T 1346-2011 [43].

\subsubsection{Compressive Strength}

With the same preparation method as above, the binary binders were placed in $(40 \times 40 \times 40) \mathrm{mm}$ molds and cured in the cement concrete standard curing box at $20 \pm 1{ }^{\circ} \mathrm{C}$ and $90 \%$ relative humidity. After $4 \mathrm{~h}$, the specimens were demoulded and then cured in water at $20 \pm 1{ }^{\circ} \mathrm{C}$ until testing. The $4 \mathrm{~h}, 1 \mathrm{~d}, 3 \mathrm{~d}, 28 \mathrm{~d}$ compressive strengths of six specimens for each mixture were tested at a rate of $1.0 \mathrm{kN} / \mathrm{s}$. 
Table 2: Mix proportion of specimens

\begin{tabular}{lllll}
\hline Code & SAC/g & Micro-IOTs/g & Water/binder & PCE/g \\
\hline 1 & 300 & 0 & 0.4 & 0.45 \\
2 & 294 & 6 & 0.4 & 0.39 \\
3 & 188 & 12 & 0.4 & 0.33 \\
4 & 276 & 24 & 0.4 & 0.21 \\
\hline
\end{tabular}

After the strength test, some small pieces in the middle of the specimen were immediately immersed in absolute ethanol. These pieces were prepared for SEM and MIP measurements. In addition, part of the sample was ground into powder by hand in an agate jar, and the powder was used for XRD analysis and TG analysis.

\subsubsection{Hydrates Analysis}

The hydration products were tested by XRD and TGA. The XRD measurement was operated at $200 \mathrm{~mA}$ and $45 \mathrm{KV}$ with $\mathrm{Cu} \mathrm{Ka}$ radiation (ranging from $5^{\circ}$ to $80^{\circ}$, step size $=0.5^{\circ}$ ). The TGA was carried out using a comprehensive thermal analyzer (STA449F1, made by NETZSCH, Germany) with a temperature range from 25 to $1000^{\circ} \mathrm{C}\left(10^{\circ} \mathrm{C} / \mathrm{min}\right)$. The heating velocity was $10^{\circ} \mathrm{C} / \mathrm{min}$, and the protective gas was $\mathrm{N}_{2}$.

\subsubsection{Pore Structure Analysis}

The pore structure characteristics of the paste samples were determined by mercury porosimeter (AutoPore IV 9500, made by Micromeritics, USA). The paste specimens were broken into 5-8 mm block particles for the test. The maximum pressure was $6000 \mathrm{psi}$, and the contact angle was $130^{\circ}$.

\section{Results and Discussion}

\subsection{Properties of Micro-IOTs}

The particle size distribution of RIOTs, SAC, and micro-IOTs is presented in Fig. 1. It was found that the average diameter of micro-IOTs was $517 \mathrm{~nm}$, indicating that IOTs slurry with micro-scale could be obtained by wet grinding. Besides, it was seen that the particle size of micro-IOTs was far smaller than that of SAC, which was conducive to its filling effect in SAC system.

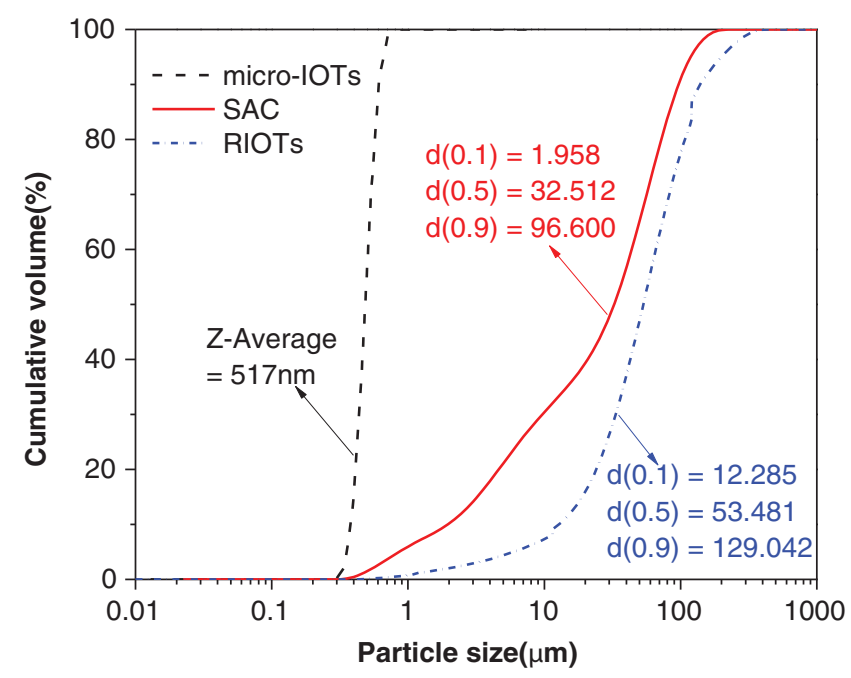

Figure 1: Particle sizes of RIOTs, SAC and micro-IOTs 
The XRD patterns of RIOTs and micro-IOTs are presented in Fig. 2. The main crystalline phases were silicon dioxide, grunerite and katophorite, and the diffraction peak intensity of the phases in micro-IOTs was much lower than that in RIOTs. This indicated that the crystalline degree in IOTs was decreased, and the amorphous phase was increased with the wet grinding process.

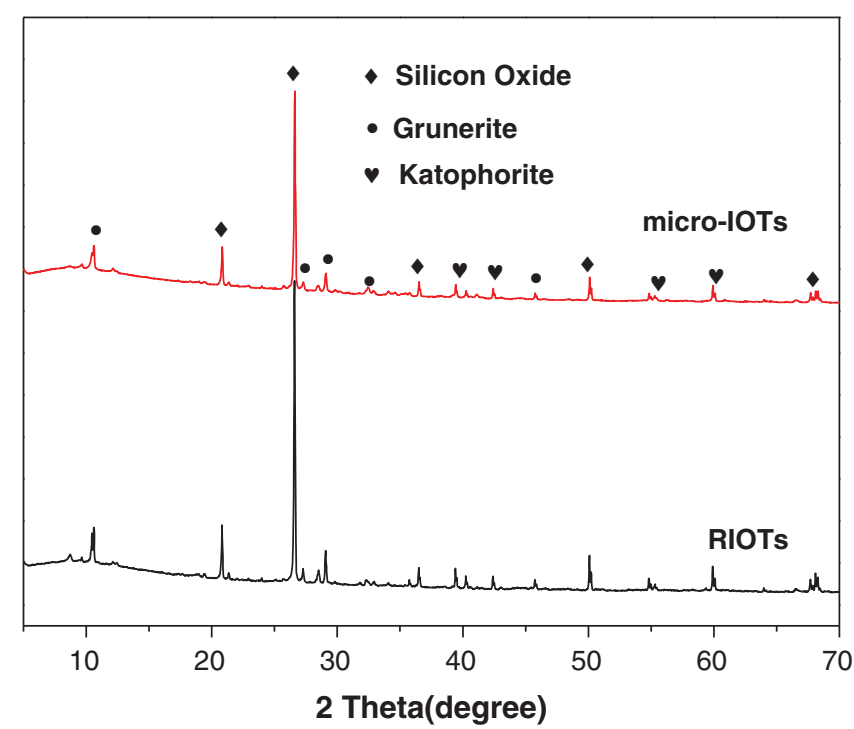

Figure 2: XRD patterns of RIOTs and micro-IOTs

The influence of wet grinding on IOTs surface characteristics was studied by XPS analysis, and highresolution scan curves of RIOTs and micro-IOTs for Si2p, A12p, and O1s were displayed in Fig. 3. The binding energy of silicon was reduced from 102.78 to $102.48 \mathrm{eV}$, and that of aluminum and oxygen was respectively reduced from 74.33 to $73.78 \mathrm{eV}$ and from 531.98 to $531.68 \mathrm{eV}$ after wet grinding. The decrease in binding energy indicated that atoms' coupling to electrons was weakened, and chemical bonds were vulnerable to break.

Based on the above results, micro-IOTs have changed physical properties and complex chemical reactions during wet grinding. Firstly, wet grinding significantly decreased the particle size, which is beneficial to play nucleation and filling effects in cement-based materials. Secondly, the mechanical breakage helps decrease silicon dioxide crystallinity in IOTs and improves amorphous phase of physical structure. Moreover, the wet milling decreased the bonding energy, indicating that a chemical reaction occurred during wet grinding. These would contribute to increasing reactivity of micro-IOTs in cement and concrete materials. Similar changes in physical and chemical properties have also been reported in previous research on wet grinding treatment of fly ash [39]. These changes provided the possibility to apply micro-IOTs in improving SAC performance.

\subsection{Setting Time of Micro-IOTs-SAC System}

The setting time of SAC pastes with different content of micro-IOTs is presented in Fig. 4. It was observed that the initial setting times and final setting times were gradually shortened with increasing micro-IOTs content, demonstrating that micro-IOTs could obviously accelerate the setting and hardening of SAC paste. Since the paste setting depends on the early hydration rate of SAC [44], the shortened setting time showcased that the early hydration of SAC could be accelerated by adding micro-IOTs. The shortening of setting time could be ascribed to the nucleation effect of micro-IOTs particles. It was widely accepted that nanoparticles and microparticles could act as nucleation seeds to accelerate cement's 
hydration. After wet grinding, the particles of IOTs were significantly refined, and the micro-IOTs with an average diameter of $517 \mathrm{~nm}$ were obtained (Fig. 1). These microparticles could fill the voids of dehydrated SAC particles, offer more nucleation sites for growing hydration products, hasten the early hydration, and help microstructure form skeleton faster, thereby shortening the setting time.
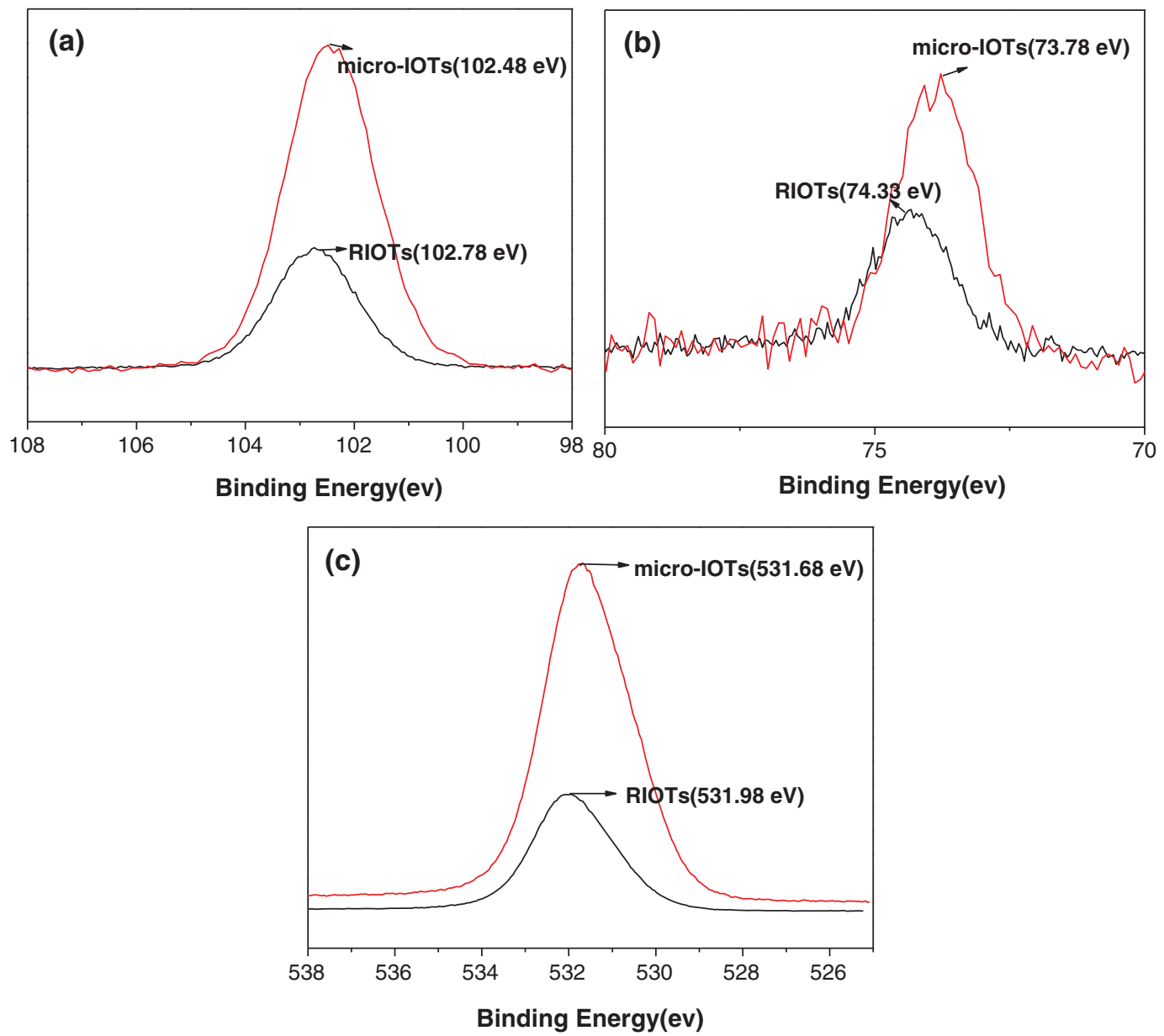

Figure 3: XPS (Si, Al, O) of RIOTs, SAC and micro-IOTs (a) Si2p; (b) Al2p; (c) O1s

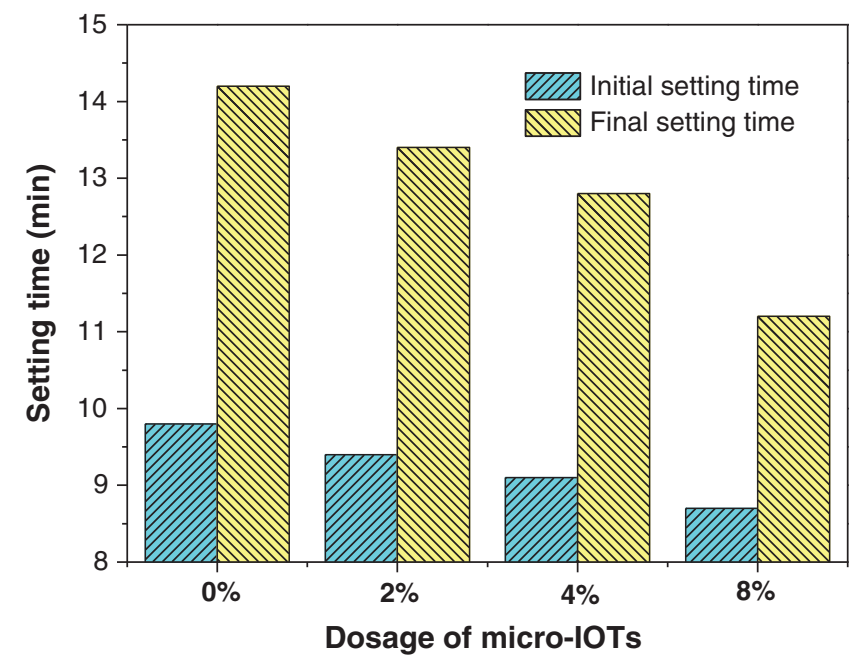

Figure 4: Effect of micro-IOTs on setting time of SAC paste 


\subsection{Compressive Strength}

The average compressive strengths of SAC pastes comprising different content of micro-IOTs are illustrated in Fig. 5. The content of micro-IOTs significantly impacts the compressive strength of microIOTs-SAC binary system. When the replacement ratio is $2 \%$, the compressive strengths at $4 \mathrm{~h}, 1 \mathrm{~d}, 3 \mathrm{~d}$, $28 \mathrm{~d}$ respectively improved by $22 \%, 16 \%, 15 \%$, and $10 \%$ compared with those of pure SAC paste. Moreover, when the replacement ratio was $4 \%$, compressive strengths of binary system were respectively higher, about $4 \%, 4 \%, 1 \%$, and $2 \%$, than the control group. These results specified that adding low amounts of micro-IOTs to SAC could notably improve SAC's early strength and was also suitable for developing later strength. This was because micro-IOTs served as ultra-fine grains, filling the voids around the clinker particles and micropores of hydration products, making the microstructure more compact. Furthermore, micro-IOTs provided a great number of nuclear sites to accelerate SAC's reaction, thus rapidly provide hydration products. These physical effects of micro-IOTs in SAC could increase the bonding force between cement and cement, contributing to the compressive strength growth.

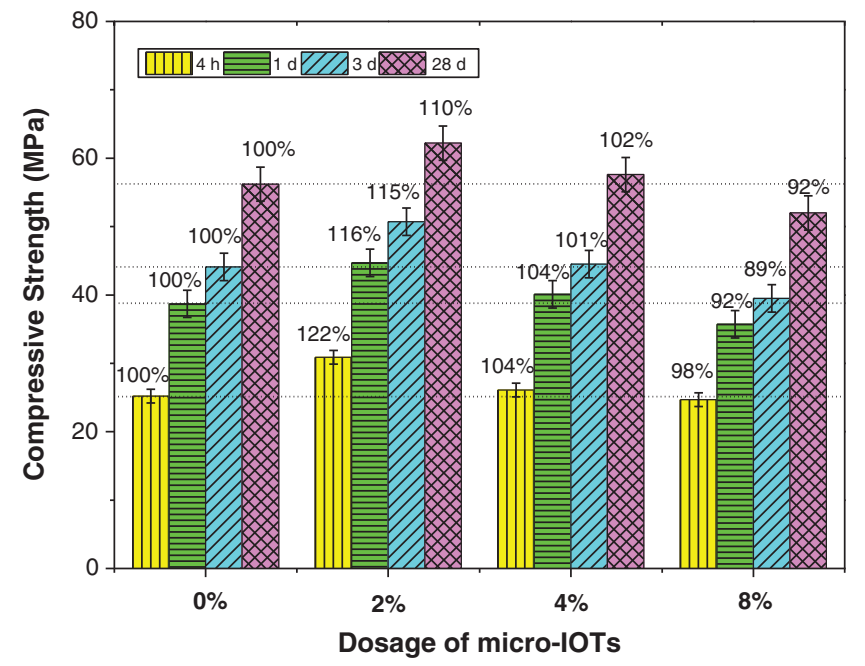

Figure 5: Effect of micro-IOTs on compressive strength of SAC paste

Besides, when the replacement ratio was $8 \%$, the binary system's compressive strengths at all ages were lower than that of pure SAC paste. Two reasons were speculated: one was that excessive micro-IOTs would reduce the relative content of SAC in the system, thus reducing SAC contribution to the compressive strength. Another possibility was that excessive micro-IOTs were unevenly dispersed, leading to defects in samples and then affecting pastes' strengths.

From the above analysis, adding low amounts of micro-IOTs indeed reduced the setting time and improved SAC pastes' compressive strengths at all ages. According to previous reports [26,30], the early strength of SAC is closely associated with hydration degree and hydration products' microstructure, and later strength maintenance is closely linked to stability of hydrated products and pore structure. A detailed analysis of the mechanism on micro-IOTs, improving the compressive strength of SAC under $2 \%$ microIOTs dosage, has been given as follows.

\subsection{Phase Analysis}

The main hydration products of micro-IOTs-SAC system at different curing times were studied by XRD and TG-DTG analyses. 
The main components of the SAC are ye'elimite $\left(C_{4} A_{3} \bar{S}\right)$ and anhydrite $\left(C \bar{S} H_{2}\right)$. According to the previous literature [45], if the proportion of anhydrite is relatively high, the reaction of ye'elimite was shown in Eq. (1). On the contrary, when the anhydrite content was fewer or absent, the reaction of ye'elimite was shown in Eq. (2).

$\mathrm{C}_{4} A_{3} \bar{S}+2 \mathrm{C} \bar{S} H_{2}+34 H \rightarrow C_{6} A \bar{S}_{3} H_{32}+2 A H_{3}$

$\mathrm{C}_{4} A_{3} \bar{S}+18 \mathrm{H} \rightarrow \mathrm{C}_{4} A \bar{S} H_{12}(A F m)+2 A H_{3}$

Fig. 6 shows XRD patterns of SAC and micro-IOTs-SAC at ages of $4 \mathrm{~h}, 3 \mathrm{~d}$, and $28 \mathrm{~d}$. The hydration phases of SAC and micro-IOTs-SAC were basically the same, highlighting that micro-IOTs could not change hydration products' phases. The main hydrate was ettringite, and dehydrated products, including ye'elimite, larnite and anhydrite, were also presented. It can be seen that the peak intensity of ye'elimite decreased with the curing age. Conversely, the peak intensity of ettringite was significantly increased. Besides, because several peaks overlapped, identifying other phases was difficult in XRD analysis. However, the dispersion peak at the bottom revealed the possibility of forming poorly crystalline monosulfate (AFm) and aluminum hydroxide $\left(\mathrm{AH}_{3}\right)$.
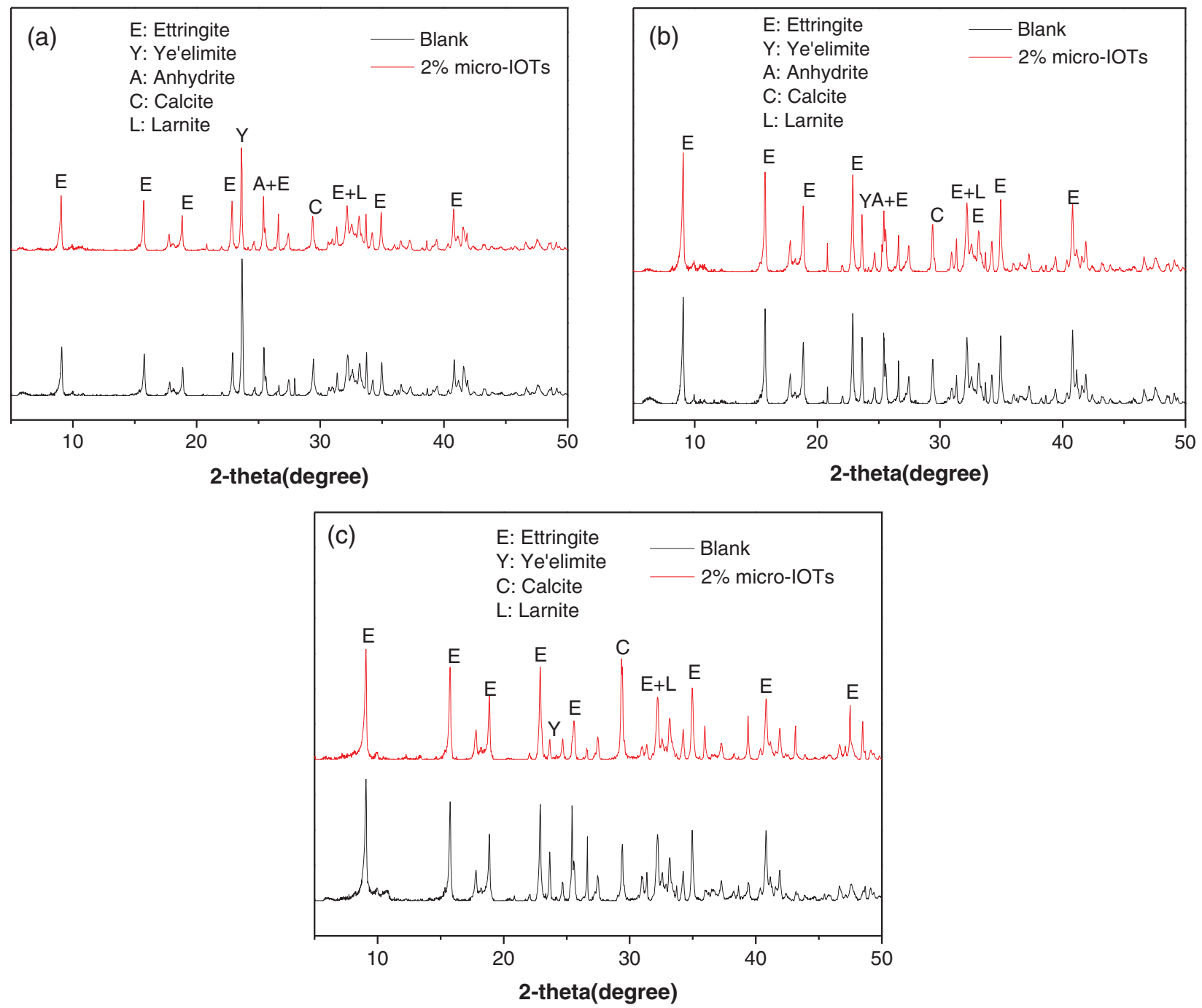

Figure 6: XRD patterns of paste samples (a) 4 h; (b) 3 d; (c) $28 \mathrm{~d}$ 
Furthermore, the differences in hydration between SAC and micro-IOTs-SAC could also be observed clearly at the same curing age. The peak intensity of ettringite in micro-IOTs-SAC pastes was higher than that in pure SAC, and the peak intensity of ye'elimite in micro-IOTs-SAC was lower than that in pure $\mathrm{SAC}$, especially for $4 \mathrm{~h}$ and $3 \mathrm{~d}$ (see Figs. $6 \mathrm{~b}$ and $6 \mathrm{c}$ ). It revealed that micro-IOTs could accelerate ettringite formation and hasten hydration of SAC minerals at early ages, which was because micro-IOTs could provide more nucleation sites for ettringite during this period. According to Hargis et al. [45], $\mathrm{AH}_{3}$ gel was confirmed to be fragile at hydration beginning, and ettringite content was the most critical factor affecting the strength development of SAC. The higher the ettringite content is, the greater the early strength of SAC is [46]. Incorporating micro-IOTs promoted ettringite formation, which contributed to higher compressive strength in SAC with low additions of micro-IOTs at early ages. Besides, Fig. 6c demonstrates that anhydrite in cement is fully hydrated after $28 \mathrm{~d}$, and the diffraction ettringite peak is not higher than $3 \mathrm{~d}$, specifying that the hydration reaction is basically stable after $28 \mathrm{~d}$.

Since some amorphous and poor crystalline products are difficult to be distinguished using XRD due to poor crystallinity, the hydration products were further analyzed by TG. TG-DTG analysis of SAC and microIOTs-SAC system at $4 \mathrm{~h}, 3 \mathrm{~d}$, and $28 \mathrm{~d}$ is depicted in Fig. 7. At the same age, the overall mass loss of microIOTs-SAC system was more than that of SAC. For instance, the overall mass loss at ages of $4 \mathrm{~h}, 3 \mathrm{~d}$, and $28 \mathrm{~d}$ was $22.36 \mathrm{wt} \%, 28.32 \mathrm{wt} \%$, and $29.39 \mathrm{wt} \%$ in micro-IOTs-SAC system compared with $20.62 \mathrm{wt} \%, 27.56 \mathrm{wt}$ $\%$, and $29.05 \mathrm{wt} \%$ in pure SAC, respectively. The overall mass loss could directly prove the accelerating effect of micro-IOTs on SAC hydration. It indicated that adding micro-IOTs enhanced ye'elimite dissolution and induced precipitating more hydration products.

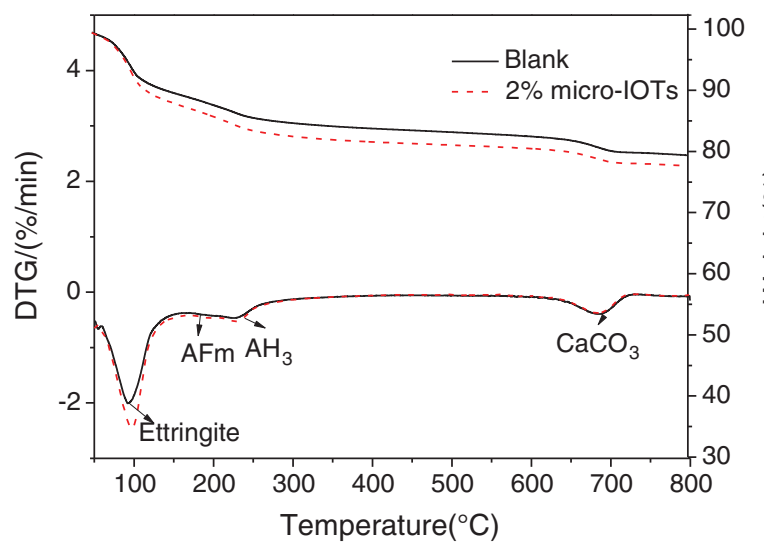

(a)

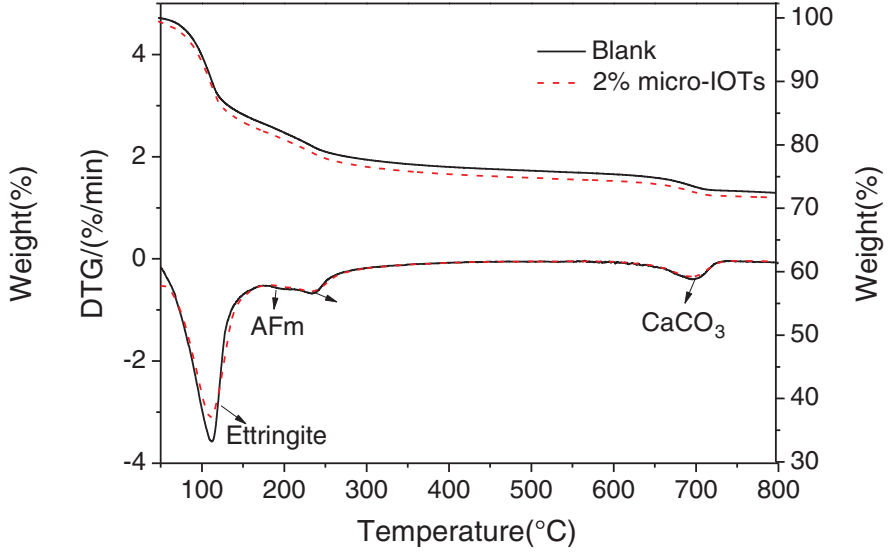

(b)

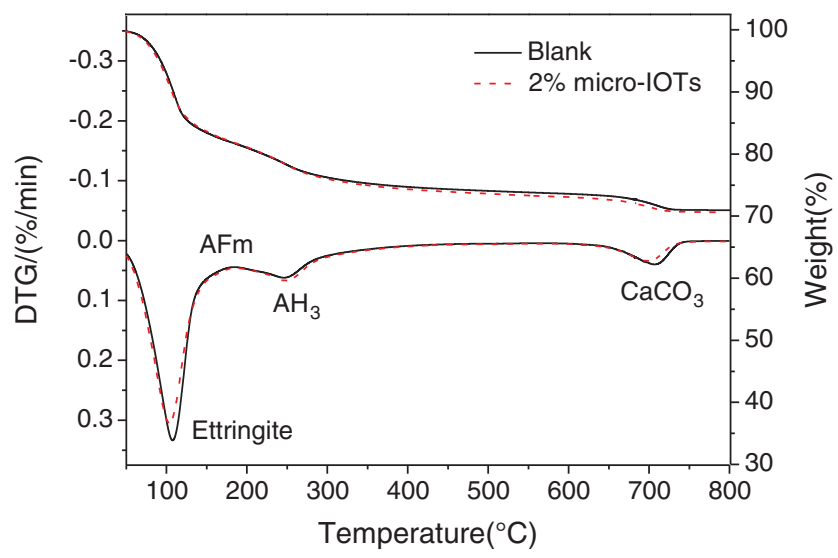

(c)

Figure 7: TG/DTG curve of samples at 4 h, $3 \mathrm{~d}$ and $28 \mathrm{~d}$ (a) 4 h; (b) $3 \mathrm{~d}$; (c) $28 \mathrm{~d}$ 
Moreover, three weight loss peaks could be observed obviously from the DTG curve. According to previous literature [47-49], the mass loss peak at $100-150^{\circ} \mathrm{C}$ was ascribed to ettringite decomposition, and that at $250-280^{\circ} \mathrm{C}$ was mainly because of $\mathrm{AH}_{3}$ dehydration. The peak at $600-800^{\circ} \mathrm{C}$ was assigned to calcium carbonate decomposition produced by carbonation during sample preparation or curing. Besides, the weak peak around $160-200^{\circ} \mathrm{C}$ could be ascribed to AFm [48].

The calculated weight loss of ettringite at $100-150^{\circ} \mathrm{C}$ was presented in Fig. 8a. Adding micro-IOTs was found to increase the weight loss by $23 \%$ and $2 \%$ at $4 \mathrm{~h}$ and $3 \mathrm{~d}$, compared with pure SAC paste. The microIOTs promoted ettringite formation at early age, consistent with XRD results. This could conclude that pastes containing micro-IOTs exhibited higher compressive strength at the early stage.
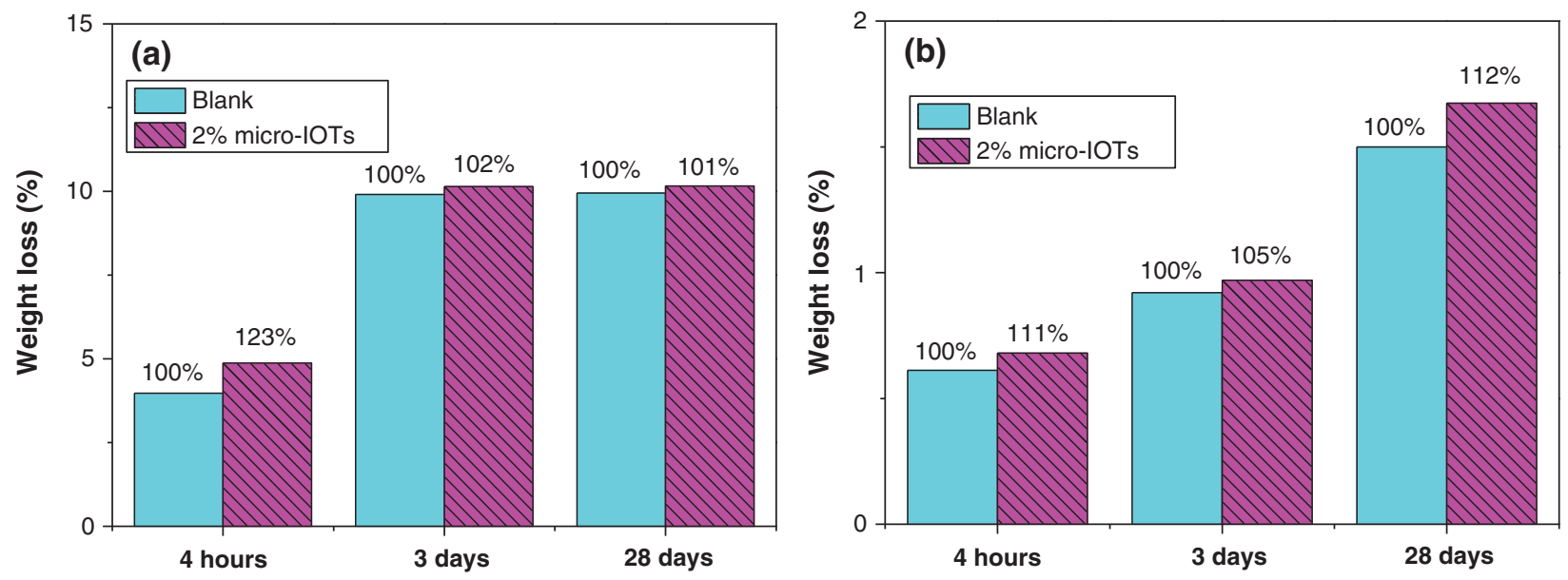

Figure 8: The weight loss of pastes at (a) $100-150^{\circ} \mathrm{C}$; (b) $250-280^{\circ} \mathrm{C}$

Furthermore, the weight loss of $\mathrm{AH}_{3}$ at $250-280^{\circ} \mathrm{C}$ was calculated and illustrated in Fig. $8 \mathrm{~b}$. At ages of $4 \mathrm{~h}, 3 \mathrm{~d}$, and $28 \mathrm{~d}$, micro-IOTs increased the content of $\mathrm{AH}_{3}$ by $11 \%, 5 \%$, and $12 \%$ compared to the blank. $\mathrm{AH}_{3}$ was found to have a small contribution to the early strength of SAC but had a more significant impact on later strength. According to previous research [50], the more the content of $\mathrm{AH}_{3}$, the less the content of ettringite, the higher the compressive strength of SAC at $28 \mathrm{~d}$. Fig. 8a showcases that although ettringite's content in $28 \mathrm{~d}$ of the sample containing micro-IOTs was similar to that of pure SAC sample, higher content of $\mathrm{AH}_{3}$ could be filled in ettringite pores to ensure later SAC strength. Therefore, the higher content of $\mathrm{AH}_{3}$ in micro-IOTs-SAC was one of the reasons for strength development at $28 \mathrm{~d}$.

\subsection{Pore Structures}

The pore structures of hardened paste samples were revealed using MIP. The results of porosity, median pore size, and cumulative pore volumes are shown in Table 3, and the pore size distribution results are presented in Fig. 9.

Table 3: Properties of the pores in SAC and micro-IOTs-SAC specimens

\begin{tabular}{lllll}
\hline Age & Sample & $\begin{array}{l}\text { cumulative pore } \\
\text { volumes }\left(\mathrm{mL} \cdot \mathrm{g}^{-1}\right)\end{array}$ & $\begin{array}{l}\text { Porosity } \\
(\%)\end{array}$ & $\begin{array}{l}\text { Median diameter } \\
(\text { volume })(\mathrm{nm})\end{array}$ \\
\hline $4 \mathrm{~h}$ & SAC & 0.2426 & 35.73 & 82.6 \\
$4 \mathrm{~h}$ & micro-IOTs-SAC & 0.2312 & 35.09 & 61.8 \\
$28 \mathrm{~d}$ & SAC & 0.2035 & 30.59 & 87.8 \\
$28 \mathrm{~d}$ & micro-IOTs-SAC & 0.2036 & 31.19 & 64.8 \\
\hline
\end{tabular}



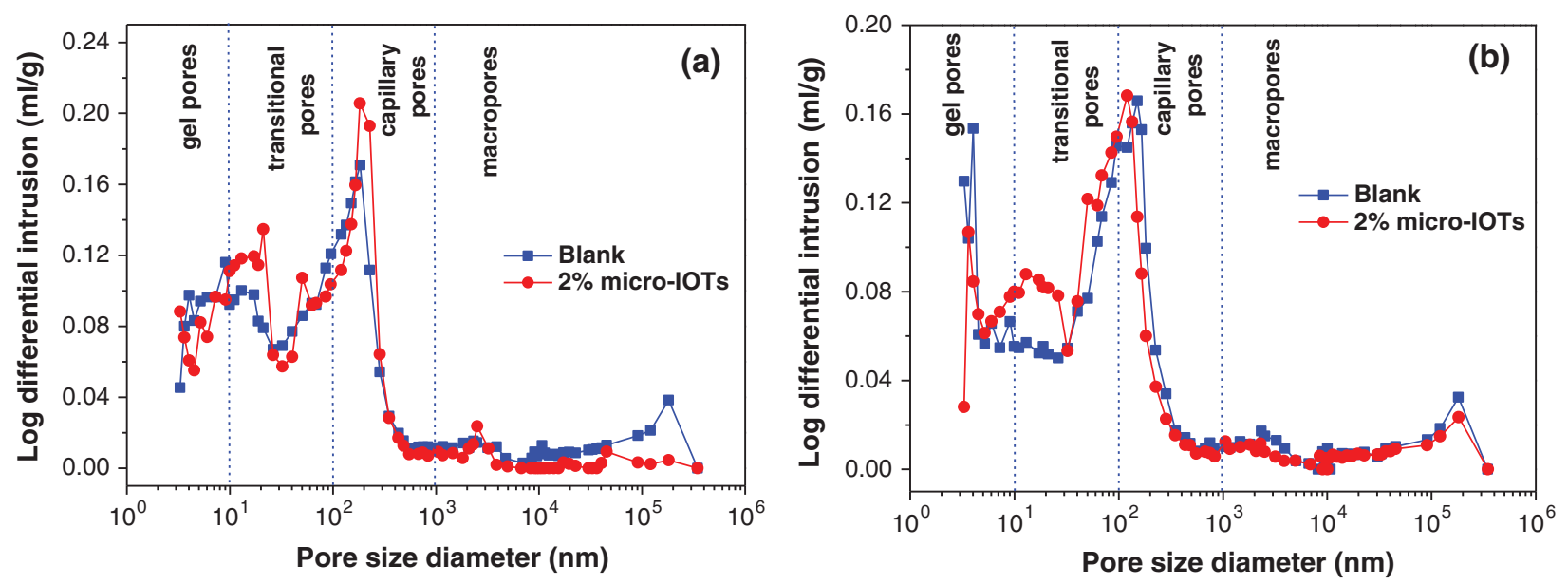

Figure 9: Pore distribution of $4 \mathrm{~h}$ and $28 \mathrm{~d}$ samples (a) $4 \mathrm{~h}$; (b) $28 \mathrm{~d}$

At the age of $4 \mathrm{~h}$, cumulative pore volumes of paste were found to decrease by $13 \%$ (from 0.2426 to $0.2312 \mathrm{~mL} / \mathrm{g}$ ), and porosity decreased from $35.73 \%$ to $35.09 \%$ with adding $2.0 \%$ micro-IOTs. Moreover, the median diameter (volume) of reference group was $82.6 \mathrm{~nm}$, while that of SAC mixed with $2 \%$ microIOTs was $61.8 \mathrm{~nm}$. These findings highlighted that micro-IOTs could reduce the total porosity and refine the pore structure of SAC at an early age. Moreover, according to previous reports [26], the pores in cement-based materials are generally divided into four types: macropores (diameter $\geq 1000 \mathrm{~nm}$ ), capillary pores (diameters, 100-1000 nm), transitional pores (diameter, 10-100 nm), and gel pores (diameters $\leq 10 \mathrm{~nm}$ ). It can be observed from Fig. 9a that micro-IOTs significantly decreased the number of macropores and increased the number of transitional pores. It is assumed that the larger pores represent the spaces in the unhydrated cement particles, and the smaller pores represent the spaces between the hydration products [51]. Since the uniformly distributed micro-IOTs could serve as a nucleation site for the hydration product of SAC, it was beneficial to accelerating the early hydration of SAC, thus producing dense microstructure in micro-IOTs-SAC system [52]. These results further explained the reason why micro-IOTs could improve SAC's early strength.

The results at 28 days seemed to be different as few changes were found in cumulative pore volumes of pastes without micro-IOTs or with $2 \%$ micro-IOTs, and porosity increased from $30.59 \%$ to $31.19 \%$ with adding 2.0\% micro-IOTs. However, adding micro-IOTs reduced the median diameter from $87.8 \mathrm{~nm}$ in blank to $64.8 \mathrm{~nm}$. Adding micro-IOTs shifted the differential intrusion curves from larger pores to smaller pores. It was seen from Fig. 9b that micro-IOTs significantly refined both capillary pores and decreased the number of macropores. These results demonstrated that adding micro-IOTs was beneficial to pore structure refinement of SAC pastes in the later stage, which was related to the filling effect of micro-IOTs and the accelerated hydration of SAC via nucleation effect. It was reported that MIP could only detect interconnected pores [53]. Capillary pores and macropores were easily blocked by micro IOT and hydration products (including additional $\mathrm{AH}_{3}$ ), resulting in interconnection pore decrease and pore structure improvement. This is an important reason why the incorporation of micro-IOT caused the increase in later strength.

\subsection{SEM Analysis}

Fig. 10 displays SEM images of hydrated samples at different ages. As demonstrated in Fig. 10a, after $4 \mathrm{~h}$ of hydration, loose micro morphology and needle-like ettringite with a very low draw ratio were observed from the pure SAC sample. However, ettringite morphology in the sample with $2 \%$ micro-IOTs was mainly 
ribbon-like and columnar, and only a few were needle-like, which was remarkably different from ettringite morphology in the pure SAC. According to a previous report [33], similar ribbon-like ettringite was also observed in the SAC paste with graphene oxide (GO), and formation and growth of ribbon-like ettringite further led to improved early strength of GO-SAC. As depicted in Fig. 10b, the ribbon-like crystals and needle crystals tended to crisscross and interweave from different directions, which helped develop early strength.
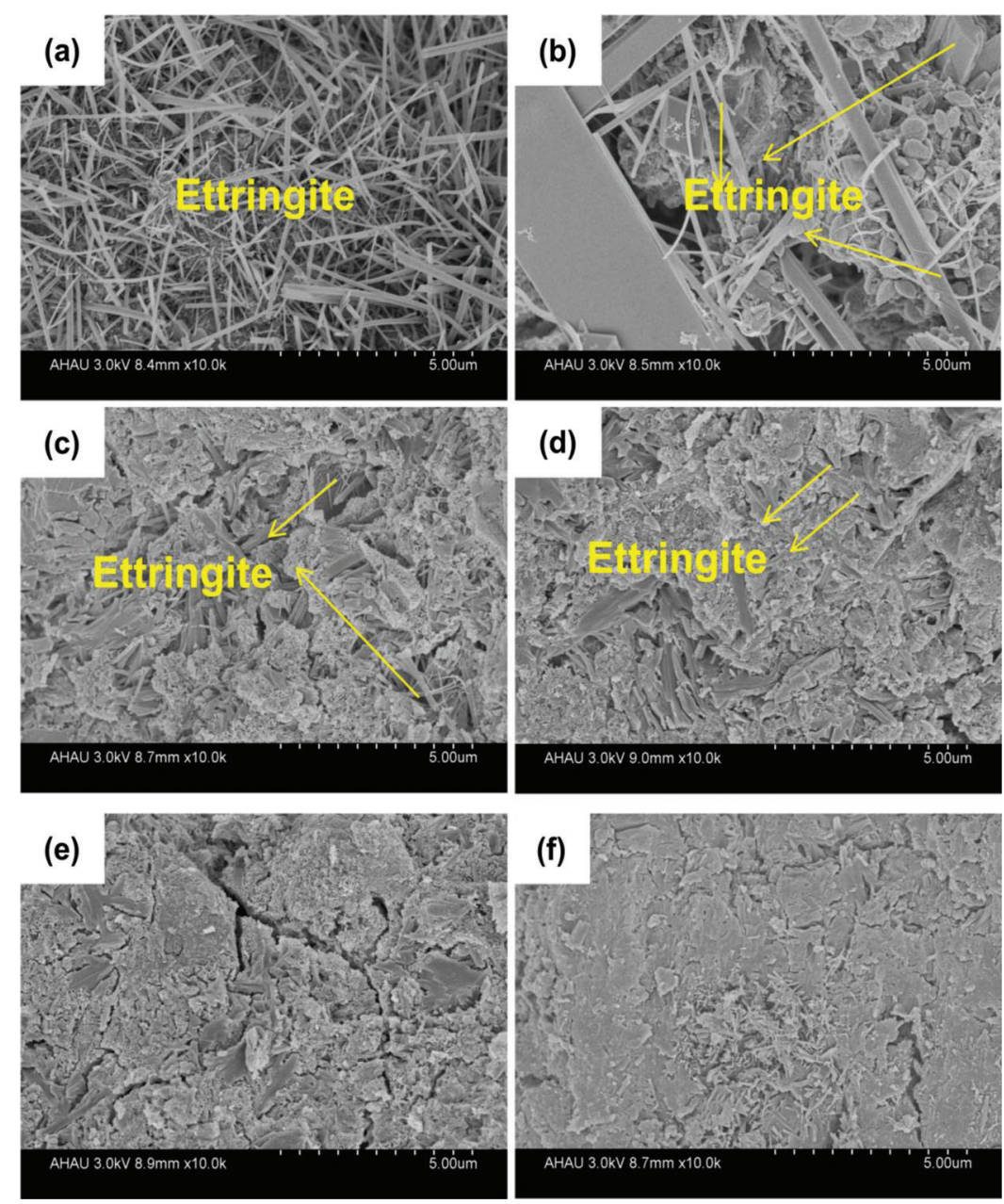

Figure 10: SEM micrographs of (a) SAC specimens at $4 \mathrm{~h}$; (b) micro-IOTs-SAC specimens at $4 \mathrm{~h}$; (c) SAC specimens at $3 \mathrm{~d}$; (d) micro-IOTs-SAC specimens at $3 \mathrm{~d}$; (e) SAC specimens at $28 \mathrm{~d}$; (f) micro-IOTs-SAC specimens at $28 \mathrm{~d}$

After $3 \mathrm{~d}$ of hydration, the sample's microstructure containing $2 \%$ micro-IOTs displayed a more dense structure and fewer voids than the pure SAC sample. Moreover, ettringite was distributed randomly in the aluminum hydroxide matrix that covered it to a great extent. Besides, some needle-like ettringite still could be observed from the pure SAC sample in Fig. 10c, while almost all of the ettringite in the samples with micro-IOTs were columnar in Fig. 10d. It was reported that columnar ettringite was more conducive to SAC strength's stability in a later stage than needle-like ettringite [50]. At the age of $28 \mathrm{~d}$, the pure SAC sample presented a loose structure with several pores, while the microstructure of pastes containing $2 \%$ micro-IOTs manifested a more compact structure, consistent with pore structures. These also provided 
viewable evidence that the growth of compressive strengths was closely correlated with higher hydration degree of SAC and more stable ettringite at ages of $3 \mathrm{~d}$ and $28 \mathrm{~d}$.

Since ettringite is the main hydration product of SAC, its content and morphology have an important influence on SAC performance. It was confirmed that the early strength of SAC mainly depended on the mechanical occlusion between the ettringite crystal clusters, and the late strength was closely related to ettringite stability [45]. The addition of micro-IOTs changed the hydration environment and formed a new morphology hydrate (ribbon-like ettringite), see Fig. 10b. Meanwhile, the ettringite intertwined to form a network structure, leading to improved early strength of SAC. Moreover, more columnar ettringite and higher degree of hydration due to micro-IOTs ensured the stable growth of late strength of SAC.

In conclusion, the use of micro-IOTs to improve SAC performance is a method of high value-added recycling and utilization of IOTs, which is worthy of popularization and application. Based on the above results, micro-IOTs, which can enhance SAC's mechanical properties and improve the pore structure of $\mathrm{SAC}$, can be used as micron mineral admixture in the SAC system to expanding the application fields of SAC. Although preparing micro-IOTs will inevitably generate some energy consumption, the total cost is much cheaper than common nanomaterials due to completely free raw materials. In addition, the microIOTs can be obtained through environmentally friendly wet milling technology [39]. Compared to traditional dry-milling, wet grinding shows higher efficiency and can avoid dust generation. Since most of IOTs are directly discharged into the river or exposed to rainwater, wet grinding can avoid the necessary pre-drying procedure in the traditional dry grinding [40]. More importantly, micro-IOTs are in a slurry state, which is easier to disperse evenly in SAC and conducive to the formation of a denser microstructure of SAC. Hence, using micro-IOTs as a mineral admixture in the SAC system is expected to be developed.

\section{Conclusions}

The findings of this study can be summarized as follows:

(1) The preparation of micro-IOTs with a Z-Average grain diameter of $517 \mathrm{~nm}$ by wet grinding technology was achieved. The crystallinity of phases in IOTs significantly decreased after wet milling, and the binding energy of silicon, aluminum, and oxygen was respectively reduced from $102.78,74.33 \mathrm{eV}$, and 531.98 to $102.48 \mathrm{eV}, 73.78$, and $531.68 \mathrm{eV}$ after wet grinding.

(2) With the increase of micro-IOTs contents, the setting times of SAC pastes decreased gradually.

(3) By adding $2 \%$ micro-IOTs, the compressive strengths of SAC pastes were enhanced by about $22 \%$, $16 \%, 15 \%$, and $10 \%$ at $4 \mathrm{~h}, 1 \mathrm{~d}, 3 \mathrm{~d}$, and $28 \mathrm{~d}$, respectively.

(4) Compared to the blank, the incorporation of $2 \%$ micro-IOTs improved the contents of ettringite by $23 \%$ and led to ribbon-like ettringite formation at $4 \mathrm{~h}$. Meanwhile, the $\mathrm{AH}_{3}$ content increased by $11 \%$ and $12 \%$ at $4 \mathrm{~h}$ and $28 \mathrm{~d}$.

(5) Adding $2 \%$ micro-IOTs could reduce the total porosity of hardened SAC pastes at an early age and refine the pore structure at a later age, thus improving their compressive strengths to varying degrees at different ages.

(6) Using micro-IOTs as a mineral admixture in the SAC system provides a high value-added recycling method for IOTs.

Funding Statement: This work was supported by University Natural Science Research Project of Anhui Province (KJ2019A0171); National Natural Science Foundation of China (Grant No. 52005009); Anhui Province Natural Science Funds for Youth Fund Project (2008085QE273); and Anhui Province Key Research and Development Project (202004e11020003). 
Conflicts of Interest: The authors declare that they have no conflicts of interest to report regarding the present study.

\section{References}

1. Cheng, Y. H., Huang, F., Li, W. C., Liu, R., Li, G. L. et al. (2016). Test research on the effects of mechanochemically activated iron tailings on the compressive strength of concrete. Construction and Building Materials, 118(5), 164-170. DOI 10.1016/j.conbuildmat.2016.05.020.

2. Luo, L., Zhang, Y. M., Bao, S. X., Chen, T. J. (2016). Utilization of iron ore tailings as raw material for portland cement clinker production. Advances in Materials Science and Engineering, 2016, 1-6. DOI 10.1155/2016/ 1596047.

3. Yao, G., Wang, Q., Wang, Z., Wang, J., Lyu, X. (2020). Activation of hydration properties of iron ore tailings and their application as supplementary cementitious materials in cement. Powder Technology, 360, 863-871. DOI 10.1016/j.powtec.2019.11.002.

4. Jiang, P., Qiu, L., Li, N., Wang, W., Zhou, A. et al. (2018). Shearing performance of lime-reinforced iron tailing powder based on energy dissipation. Advances in Civil Engineering, 2018, 1-8. DOI 10.1155/2018/4748526.

5. Liu, J. H., Zhou, Y. C., Wu, A. X., Wang, H. J. (2019). Reconstruction of broken Si-O-Si bonds in iron ore tailings (IOTs) in concrete. International Journal of Minerals, Metallurgy, and Materials, 26(10), 1329-1336. DOI 10.1007/s12613-019-1811-z.

6. Mendes Protasio, F. N., Ribeiro de Avillez, R., Letichevsky, S., de Andrade Silva, F. (2021). The use of iron ore tailings obtained from the Germano dam in the production of a sustainable concrete. Journal of Cleaner Production, 278, 123929. DOI 10.1016/j.jclepro.2020.123929.

7. Li, C., Sun, H. H., Bai, J., Li, L. T. (2010). Innovative methodology for comprehensive utilization of iron ore tailings Part 1. The recovery of iron from iron ore tailings using magnetic separation after magnetizing roasting. Journal of Hazardous Materials, 174(1-3), 71-77. DOI 10.1016/j.jhazmat.2009.09.018.

8. Li, C., Sun, H. H., Yi, Z. L., Li, L. T. (2010). Innovative methodology for comprehensive utilization of iron ore tailings Part 2: The residues after iron recovery from iron ore tailings to prepare cementitious material. Journal of Hazardous Materials, 174(1-3), 78-83. DOI 10.1016/j.jhazmat.2009.09.019.

9. Li, Y., Zhang, Q., Yuan, S., Yin, H. (2021). High-efficiency extraction of iron from early iron tailings via the suspension roasting-magnetic separation. Powder Technology, 379(5), 466-477. DOI 10.1016/j. powtec.2020.10.005.

10. Tang, Z., Gao, P., Li, Y., Han, Y., Li, W. et al. (2020). Recovery of iron from hazardous tailings using fluidized roasting coupling technology. Powder Technology, 361, 591-599. DOI 10.1016/j.powtec.2019.11.074.

11. Fontes, W. C., Mendes, J. C., Da Silva, S. N., Peixoto, R. A. F. (2016). Mortars for laying and coating produced with iron ore tailings from tailing dams. Construction and Building Materials, 112(4), 988-995. DOI 10.1016/j. conbuildmat.2016.03.027.

12. Huang, X. Y., Ranade, R., Ni, W., Li, V. C. (2013). Development of green engineered cementitious composites using iron ore tailings as aggregates. Construction and Building Materials, 44(5), 757-764. DOI 10.1016/j. conbuildmat.2013.03.088.

13. Zhao, S. J., Fan, J. J., Sun, W. (2014). Utilization of iron ore tailings as fine aggregate in ultra-high performance concrete. Construction and Building Materials, 50(10), 540-548. DOI 10.1016/j.conbuildmat.2013.10.019.

14. Shettima, A. U., Hussin, M. W., Ahmad, Y., Mirza, J. (2016). Evaluation of iron ore tailings as replacement for fine aggregate in concrete. Construction and Building Materials, 120(1-3), 72-79. DOI 10.1016/j. conbuildmat.2016.05.095.

15. Das, S. K., Kumar, S., Ramachandrarao, P. (2000). Exploitation of iron ore tailing for the development of ceramic tiles. Waste Management, 20(8), 725-729. DOI 10.1016/S0956-053X(00)00034-9.

16. Yao, R., Liao, S. Y., Dai, C. L., Liu, Y. C., Chen, X. Y. et al. (2015). Preparation and characterization of novel glassceramic tile with microwave absorption properties from iron ore tailings. Journal of Magnetism and Magnetic Materials, 378, 367-375. DOI 10.1016/j.jmmm.2014.11.066. 
17. Fontes, W. C., de Carvalho, J. M. F., Andrade, L. C. R., Segadaes, A. M., Peixoto, R. A. F. (2019). Assessment of the use potential of iron ore tailings in the manufacture of ceramic tiles: From tailings-dams to brown porcelain. Construction and Building Materials, 206, 111-121. DOI 10.1016/j.conbuildmat.2019.02.052.

18. Cui, X. W., Wang, C. L., Ni, W., Di, Y. Q., Cui, H. L. et al. (2017). Study on the reaction mechanism of autoclaved aerated concrete based on iron ore tailings. Revista Romana De Materiale-Romanian Journal of Materials, 47(1), 46-53.

19. Liang, X. Y., Yuan, D. X., Li, J., Wang, C. L., Lin, X. R. et al. (2018). Preparation and phase characteristics of autoclaved aerated concrete using iron ore tailings. Revista Romana De Materiale-Romanian Journal of Materials, 48(3), 381-387.

20. Yang, C. M., Cui, C., Qin, J., Cui, X. Y. (2014). Characteristics of the fired bricks with low-silicon iron tailings. Construction and Building Materials, 70(4), 36-42. DOI 10.1016/j.conbuildmat.2014.07.075.

21. Li, W. S., Lei, G. Y., Xu, Y., Huang, Q. F. (2018). The properties and formation mechanisms of eco-friendly brick building materials fabricated from low-silicon iron ore tailings. Journal of Cleaner Production, 204, 685-692. DOI 10.1016/j.jclepro.2018.08.309.

22. Mendes, B. C., Pedroti, L. G., Fontes, M. P. F., Ribeiro, J. C. L., Vieira, C. M. F. et al. (2019). Technical and environmental assessment of the incorporation of iron ore tailings in construction clay bricks. Construction and Building Materials, 227, 116669. DOI 10.1016/j.conbuildmat.2019.08.050.

23. Huang, X. Y., Ranade, R., Li, V. C. (2013). Feasibility study of developing green ECC using iron ore tailings powder as cement replacement. Journal of Materials in Civil Engineering, 25(7), 923-931. DOI 10.1061/ (ASCE)MT.1943-5533.0000674.

24. Tang, C., Li, K. Q., Ni, W., Fan, D. C. (2019). Recovering iron from iron ore tailings and preparing concrete composite admixtures. Minerals, 9(4), 232. DOI 10.3390/min9040232.

25. Yao, G., Wang, Q., Su, Y. W., Wang, J. X., Qiu, J. et al. (2020). Mechanical activation as an innovative approach for the preparation of pozzolan from iron ore tailings. Minerals Engineering, 145, 106068. DOI 10.1016/j. mineng.2019.106068.

26. Yu, J., Qian, J., Tang, J., Ji, Z., Fan, Y. (2019). Effect of ettringite seed crystals on the properties of calcium sulphoaluminate cement. Construction and Building Materials, 207, 249-257. DOI 10.1016/j. conbuildmat.2019.02.130.

27. Hou, W., Liu, Z., He, F., Huang, J., Zhou, J. (2020). Sulfate diffusion in calcium sulphoaluminate mortar. Construction and Building Materials, 234(9), 117312. DOI 10.1016/j.conbuildmat.2019.117312.

28. Bernardo, G., Telesca, A., Valenti, G. L. (2006). A porosimetric study of calcium sulfoaluminate cement pastes cured at early ages. Cement and Concrete Research, 36(6), 1042-1047. DOI 10.1016/j.cemconres.2006.02.014.

29. Telesca, A., Marroccoli, M., Pace, M. L., Tomasulo, M., Valenti, G. L. et al. (2014). A hydration study of various calcium sulfoaluminate cements. Cement and Concrete Composites, 53(4), 224-232. DOI 10.1016/j. cemconcomp.2014.07.002.

30. Zhang, J., Li, G., Ye, W., Chang, Y., Liu, Q. et al. (2018). Effects of ordinary Portland cement on the early properties and hydration of calcium sulfoaluminate cement. Construction and Building Materials, 186(9), 1144-1153. DOI 10.1016/j.conbuildmat.2018.08.008.

31. Ge, Z., Yuan, H., Sun, R., Zhang, H., Wang, W. et al. (2020). Use of green calcium sulphoaluminate cement to prepare foamed concrete for road embankment: A feasibility study. Construction and Building Materials, 237(6), 117791. DOI 10.1016/j.conbuildmat.2019.117791.

32. Li, G., Liu, Q., Niu, M., Cao, L., Nan, B. et al. (2020). Characteristic of silica nanoparticles on mechanical performance and microstructure of sulphoaluminate cement/ordinary Portland cement binary blends. Construction and Building Materials, 242(1), 118158. DOI 10.1016/j.conbuildmat.2020.118158.

33. Liu, Y., Jia, M., Song, C., Lu, S., Wang, H. et al. (2020). Enhancing ultra-early strength of sulphoaluminate cement-based materials by incorporating graphene oxide. Nanotechnology Reviews, 9(1), 17-27. DOI 10.1515/ ntrev-2020-0002.

34. Sun, J., Xu, Z., Li, W., Shen, X. (2017). Effect of nano- $\mathrm{SiO}_{2}$ on the early hydration of alite-sulphoaluminate cement. Nanomaterials, 7(5), 102. DOI 10.3390/nano7050102. 
35. He, X., Zheng, Z., Ma, M., Su, Y., Yang, J. et al. (2020). New treatment technology: The use of wet-milling concrete slurry waste to substitute cement. Journal of Cleaner Production, 242(6), 118347. DOI 10.1016/j. jclepro.2019.118347.

36. Tan, H., Li, M., He, X., Su, Y., Zhang, J. et al. (2020). Preparation for micro-lithium slag via wet grinding and its application as accelerator in Portland cement. Journal of Cleaner Production, 250(5), 119528. DOI 10.1016/j. jclepro.2019.119528.

37. He, X., Zheng, Z., Yang, J., Su, Y., Wang, T. et al. (2020). Feasibility of incorporating autoclaved aerated concrete waste for cement replacement in sustainable building materials. Journal of Cleaner Production, 250(4), 119455. DOI 10.1016/j.jclepro.2019.119455.

38. Zhang, J., Tan, H., He, X., Yang, W., Deng, X. et al. (2019). Compressive strength and hydration process of ground granulated blast furnace slag-waste gypsum system managed by wet grinding. Construction and Building Materials, 228(1), 116777. DOI 10.1016/j.conbuildmat.2019.116777.

39. Yang, J., Huang, J., Su, Y., He, X., Tan, H. et al. (2019). Eco-friendly treatment of low-calcium coal fly ash for high pozzolanic reactivity: A step towards waste utilization in sustainable building material. Journal of Cleaner Production, 238(1), 117962. DOI 10.1016/j.jclepro.2019.117962.

40. Yang, Y. C., Chen, L. Q., Mao, Y. G. (2021). Different effects of wet and dry grinding on the activation of iron ore tailings. Journal of Renewable Materials, 9(12), 2261-2276. DOI 10.32604/jrm.2021.015793.

41. China Building Materials Industry Association (2006). Sulphoaluminate Cement. GB/T 20472-2006.

42. Sharonova, O. M., Solovyov, L. A., Oreshkina, N. A., Yumashev, V. V., Anshits, A. G. (2010). Composition of high-calcium fly ash middlings selectively sampled from ash collection facility and prospect of their utilization as component of cementing materials. Fuel Processing Technology, 91(6), 573-581. DOI 10.1016/j. fuproc.2010.01.003.

43. China Building Materials Federation (2011). Cement standard consistency water consumption, setting time, stability test method. GB/T 1346-2011.

44. Tan, H. B., Zhang, X., He, X. Y., Guo, Y. L., Deng, X. F. et al. (2018). Utilization of lithium slag by wet-grinding process to improve the early strength of sulphoaluminate cement paste. Journal of Cleaner Production, 205(10), 536-551. DOI 10.1016/j.jclepro.2018.09.027.

45. Hargis, C. W., Kirchheim, A. P., Monteiro, P. J. M., Gartner, E. M. (2013). Early age hydration of calcium sulfoaluminate (synthetic ye'elimite) in the presence of gypsum and varying amounts of calcium hydroxide. Cement and Concrete Research, 48(12), 105-115. DOI 10.1016/j.cemconres.2013.03.001.

46. García-Maté, M., de la Torre, A. G., León-Reina, L., Losilla, E. R., Aranda, M. A. G. et al. (2015). Effect of calcium sulfate source on the hydration of calcium sulfoaluminate eco-cement. Cement and Concrete Composites, 55(9), 53-61. DOI 10.1016/j.cemconcomp.2014.08.003.

47. Chang, J., Zhang, Y., Shang, X., Zhao, J., Yu, X. (2017). Effects of amorphous $\mathrm{AH}_{3}$ phase on mechanical properties and hydration process of $\mathrm{C}_{4} \mathrm{~A}_{3} \mathrm{~S}_{2}-\mathrm{CSH}_{2}-\mathrm{CH}-\mathrm{H}_{2} \mathrm{O}$ system. Construction and Building Materials, 133(5), 314-322. DOI 10.1016/j.conbuildmat.2016.11.111.

48. Li, M., Lan, M., Chen, Z., Wang, J., Cui, S. et al. (2020). Research on the hydration properties of $\mathrm{C}_{4} \mathrm{~A}_{3} \mathrm{~S}-\mathrm{CSH}_{2}$ cement system at different temperatures. Materials, 13(18), 4000. DOI 10.3390/ma13184000.

49. Liu, X., Feng, P., Lyu, C., Ye, S. (2020). The role of sulfate ions in tricalcium aluminate hydration: New insights. Cement and Concrete Research, 130(12), 105973. DOI 10.1016/j.cemconres.2020.105973.

50. Chang, J., Zhang, Y., Shan, X., Zhao, J., Yu, X. (2016). Effects of $\mathrm{AH}_{3}$ phase content and hydration degree on the strength of Calcium Sulfoaluminate Cement. Journal of Building Materials, 19, 1028-1032. DOI 10.3969/j. issn.1007-9629.2016.06.013.

51. Li, C., Li, J., Telesca, A., Marchon, D., Xu, K. (2021). Effect of polycarboxylate ether on the expansion of ye'elimite hydration in the presence of anhydrite. Cement and Concrete Research, 140, 106321. DOI 10.1016/ j.cemconres.2020.106321. 
JRM, 2022, vol.10, no.4

52. Alwaeli, M., Gołaszewski, J., Niesler, M., Pizoń, J., Gołaszewska, M. (2020). Recycle option for metallurgical sludge waste as a partial replacement for natural sand in mortars containing CSA cement to save the environment and natural resources. Journal of Hazardous Materials, 398(15), 123101. DOI 10.1016/j. jhazmat.2020.123101.

53. Nunes, C., Sližǩková, Z., Stefanidou, M., Němeček, J. (2016). Microstructure of lime and lime-pozzolana pastes with nanosilica. Cement and Concrete Research, 83(2), 152-163. DOI 10.1016/j.cemconres.2016.02.004. 